\title{
Measurement of Circulating 25-Hydroxy Vitamin D Using Three Commercial Enzyme-Linked Immunosorbent Assay Kits with Comparison to Liquid Chromatography: Tandem Mass Spectrometry Method
}

\author{
Cheng-Shiun He, ${ }^{1}$ Michael Gleeson, ${ }^{1}$ and William D. Fraser ${ }^{2}$ \\ ${ }^{1}$ School of Sport, Exercise and Health Sciences, Loughborough University, Leicestershire, Loughborough LE11 3TU, UK \\ ${ }^{2}$ Norwich Medical School, University of East Anglia, Norwich NR4 7TJ, UK
}

Correspondence should be addressed to Michael Gleeson; m.gleeson@lboro.ac.uk

Received 26 June 2013; Accepted 17 July 2013

Academic Editors: H. Kalhoff and C. Soulage

Copyright (C) 2013 Cheng-Shiun He et al. This is an open access article distributed under the Creative Commons Attribution License, which permits unrestricted use, distribution, and reproduction in any medium, provided the original work is properly cited.

\begin{abstract}
Aim. The purpose of this study was to compare the accuracy and clinical implications of three commercial enzyme-linked immunosorbent assay (ELISA) kits (Eagle Biosciences, Immundiagnostik, and MicroVue) with a validated liquid chromatographytandem mass spectrometry (LC-MS/MS) method for the measurement of serum 25(OH)D concentration. Methods. Blood samples were obtained from 225 healthy individuals who were recruited as subjects from Loughborough University, UK. Plasma samples were measured for 25(OH)D concentration by means of LC-MS/MS and ELISA kits from Eagle Biosciences, Immundiagnostik, and MicroVue. Results. The 25(OH)D concentration measured by the Eagle Biosciences, Immundiagnostik, and MicroVue ELISAs biased $-50.9 \pm 79.1 \mathrm{nmol} / \mathrm{L},-14.2 \pm 91.0 \mathrm{nmol} / \mathrm{L}$, and $-7.2 \pm 18.9 \mathrm{nmol} / \mathrm{L}$ (bias $\pm \mathrm{SD}$ ) from the LC-MS/MS method, respectively. We found that $52 \%$ (Eagle Biosciences), 48\% (Immundiagnostik), and 38\% (MicroVue) of participants were misclassified, and the results showed the poor agreement (Kappa: $-0.201 \sim 0.251$ ) in classification of participants defined as vitamin D sufficiency and insufficiency between each method and LC-MS/MS. Conclusions. The present study demonstrated that there were negative biases and considerable misclassification of participants using the cut-off point $(50 \mathrm{nmol} / \mathrm{L})$ for vitamin $\mathrm{D}$ insufficiency and sufficiency using the Eagle Biosciences, Immundiagnostik, and MicroVue ELISAs compared with the LC-MS/MS assay.
\end{abstract}

\section{Introduction}

Recently, there have been growing demands for measurement of vitamin $\mathrm{D}$ status because of the high prevalence of vitamin D insufficiency and the discovery of vitamin $\mathrm{D}$ nonclassical functions $[1,2]$. The high prevalence of vitamin $\mathrm{D}$ insufficiency in the general population worldwide has been documented in a large number of studies [3]. Moreover, vitamin D insufficiency has also been reported to be common in athletes especially if exposure to natural sunlight is limited (e.g., when training in the winter months or when training mostly indoors) [4]. In addition, it has been recently recognised that vitamin $\mathrm{D}$ plays an important role in upregulating immunity. Several recent studies have found a negative association between vitamin $\mathrm{D}$ status and respiratory illness incidence in young and elderly adults $[5,6]$.

Measurement of plasma 25-hydroxy vitamin D $(25(\mathrm{OH}) \mathrm{D})$ concentration is widely used in clinical practice and research reports to assess vitamin D status. In humans, vitamin $\mathrm{D}$ can be obtained either from dietary sources or the epidermal layer of the skin via exposure to sunlight. Two forms of vitamin D can be obtained from dietary sources: vitamin D3 (cholecalciferol) and vitamin D2 (ergocalciferol). While vitamin D3 is found in food from animal origin, such as cod-liver oil, salmon, and egg yolk, vitamin D2 is present in some plants and fungi. The endogenously synthesised vitamin D3 and diet-derived D2 and D3 must be hydroxylated in the liver into $25(\mathrm{OH}) \mathrm{D} .25(\mathrm{OH}) \mathrm{D}$ is 
the main storage form, which can be stored in muscles and adipose tissue and is the major circulating metabolite of vitamin $\mathrm{D}$, with a plasma half-life of 2-3 weeks. Therefore, the plasma concentration of $25(\mathrm{OH}) \mathrm{D}$ is considered to be the primary indicator of vitamin D status [7]. Plasma $25(\mathrm{OH}) \mathrm{D}$ values commonly accepted as the reference range [8] are as follows. In healthy humans, $25(\mathrm{OH}) \mathrm{D}$ plasma levels > $100 \mathrm{nmol} / \mathrm{L}$ are defined as optimal vitamin D status and levels from 50 to $100 \mathrm{nmol} / \mathrm{L}$ are defined as adequate. Serum levels of $25(\mathrm{OH}) \mathrm{D}<50 \mathrm{nmol} / \mathrm{L}$ are proposed to define inadequate vitamin $\mathrm{D}$ status, and values $<30 \mathrm{nmol} / \mathrm{L}$ represent vitamin $\mathrm{D}$ deficiency.

Plasma 25(OH)D concentration can be measured by competitive protein binding assay, immunoassay, HPLC, and LC-MS/MS [1]. The LC-MS/MS method is generally considered to be the best way for the measurement of serum $25(\mathrm{OH}) \mathrm{D}$ levels because it can separate and accurately quantitate both $25(\mathrm{OH}) \mathrm{D}_{2}$ and $25(\mathrm{OH}) \mathrm{D}_{3}[2,9]$; furthermore, an extraction procedure ensures that both free $25(\mathrm{OH}) \mathrm{D}$ and protein-bound $25(\mathrm{OH}) \mathrm{D}$ are quantified. However, as the LC-MS/MS method requires expensive equipment, large plasma sample volume, and specialised staff, the commercial ELISAs are the most popular method for the measurement of plasma $25(\mathrm{OH}) \mathrm{D}$ concentration $[1,2]$. Current $25(\mathrm{OH}) \mathrm{D}$ ELISAs employ polyclonal or monoclonal antibodies that bind specifically to human $25(\mathrm{OH}) \mathrm{D}$. However, the competition between the $25(\mathrm{OH}) \mathrm{D}$ specific antibody and vitamin $\mathrm{D}$ binding protein (VDBP) in plasma samples makes these assays difficult to control and several of the most commonly used commercial ELISA kits, such as those manufactured by DiaSorin, Immunodiagnostic Systems (IDS), and Roche, have been shown to agree only poorly with LC-MS/MS $[1,2$, 10-12]. Given the recent explosion of interest in vitamin D, it seems to be necessary to establish which of the commercial ELISAs for plasma/serum $25(\mathrm{OH}) \mathrm{D}$ are the most reliable. The obvious potential advantages of these methods are their relative ease of use, low cost, and high throughput using small plasma sample volumes.

The aim of this study was to compare the accuracy and clinical implications of three commercial ELISA kits (Eagle Biosciences, Immundiagnostik, and MicroVue) with LC-MS/MS method (carried out in a validated laboratory) for the measurement of plasma $25(\mathrm{OH}) \mathrm{D}$ concentration.

\section{Methods}

2.1. Participants. A total of 225 healthy individuals were recruited as subjects from Loughborough University, UK (latitude $53^{\circ} \mathrm{N}$ ) during November 2011, in our previous vitamin $\mathrm{D}$ study with the mean age of the study cohort at recruitment being $21 \pm 3$ years (mean \pm SD). Subjects were required to complete a comprehensive health-screening questionnaire prior to starting the study and had not taken any regular medication or antibiotics in the last 3 months prior to the study. All subjects were fully informed about the rationale for the study and of all the experimental procedures to be undertaken. Subjects provided written consent to participate in the study, which had earlier received the approval of Loughborough University Ethical Advisory
Committee. For the visit to the laboratory, subjects arrived in the morning at 08:30-10:30 following an overnight fast of approximately $12 \mathrm{hrs}$, and their body mass and height were recorded. Information about the study was given to them, and they then signed an informed consent form. Subsequently, a resting venous blood sample $(12 \mathrm{~mL})$ was obtained by venipuncture from an antecubital forearm vein into the vacutainer tube (Becton Dickinson, Oxford, UK) containing $\mathrm{K}_{3}$ EDTA. Haematological analysis was immediately carried out on the EDTA sample (including haemoglobin, haematocrit and total and differential leukocyte counts) using an automated cell-counter (Ac.T 5diff haematology analyser, Beckman Coulter, High Wycombe, UK). Subjects had to have normal haematology to be included in the study. The remaining EDTA blood was centrifuged for $10 \mathrm{~min}$ at $1500 \mathrm{~g}$ and $4^{\circ} \mathrm{C}$, and the plasma was stored at $-80^{\circ} \mathrm{C}$ prior to analysis. Plasma samples were measured for $25(\mathrm{OH}) \mathrm{D}$ concentration by means of LC-MS/MS and subsequently by ELISA kits from Eagle Biosciences (Nashua, NH, USA), Immundiagnostik (Bensheim and Biomedica, Vienna, Austria), and MicroVue (Hannover, Germany).

\subsection{Liquid Chromatography: Tandem Mass Spectrometry. In} our previous vitamin D study, 225 EDTA plasma samples were analysed for $25(\mathrm{OH}) \mathrm{D}_{3}$, and $25(\mathrm{OH}) \mathrm{D}_{2}$ with a high pressure liquid chromatography tandem mass spectrometer (Waters Acuity, Manchester, UK) after a maximum of 10 months in storage with no previous freeze-thaw cycles as described previously [13]. Briefly, $25(\mathrm{OH}) \mathrm{D}_{2}, 25(\mathrm{OH}) \mathrm{D}_{3}$ and deuterated internal standard were extracted from plasma samples, following protein precipitation, using isolute C18 solid phase extraction cartridges. Potential interfering compounds were removed by initial elution with $50 \%$ methanol followed by elution of the vitamins using $10 \%$ tetrahydrofuran in acetonitrile. Dried extracts were reconstituted prior to injection into a high performance liquid chromatography tandem mass spectrometer in the multiple reaction mode (MRM). The MRM transitions $(\mathrm{m} / \mathrm{z})$ used were 413.2 > 395.3, $401.1>383.3$, and $407.5>107.2$ for $25(\mathrm{OH}) \mathrm{D}_{2}, 25(\mathrm{OH}) \mathrm{D}_{3}$ and hexadeuterated $(\mathrm{OH}) \mathrm{D}_{3}$ (internal standard), respectively. Intraassay $\mathrm{CVs}$ were $<10 \%$ across a working range of $2.5-$ $624 \mathrm{nmol} / \mathrm{L}$ for both $25(\mathrm{OH}) \mathrm{D}_{3}$ and $25(\mathrm{OH}) \mathrm{D}_{2}$. Measurements were performed in a laboratory (Norwich University Hospital, Norwich, UK) meeting the performance target set by the Vitamin D External Quality Assessment Scheme (DEQAS) Advisory Panel for 25(OH)D assays.

2.3. Eagle Biosciences. 29 randomly selected EDTA plasma samples with sufficient volume were assayed for $25(\mathrm{OH}) \mathrm{D}$ concentration using a commercially available ELISA kit (Eagle Biosciences, Nashua, NH, USA) according to the manufacturer's instructions. Briefly, the calibrators and patient samples are diluted with biotin-labelled 25(OH)D and added to microplate wells coated with monoclonal anti-25(OH)D antibodies in the first analysis step. An unknown amount of $25(\mathrm{OH}) \mathrm{D}$ in the patient sample and a known amount of biotin-labelled $25(\mathrm{OH}) \mathrm{D}$ compete for the antibody binding sites in the microplate wells plate during the incubation. Unbound $25(\mathrm{OH}) \mathrm{D}$ is removed by washing. For the detection 
of bound biotin-labelled $25(\mathrm{OH}) \mathrm{D}$, a second incubation is performed using peroxidase-labelled streptavidin. In a third incubation using the peroxidase substrate tetramethylbenzidine $(\mathrm{TMB})$, the bound peroxidase promotes a colour reaction. An acidic stopping solution is then added to stop the reaction. The colour intensity is inversely proportional to the $25(\mathrm{OH}) \mathrm{D}$ concentration. According to information supplied by the manufacturer, the intraassay CVs were $4.9 \%$ at a $25(\mathrm{OH}) \mathrm{D}$ mean concentration of $27.0 \mathrm{nmol} / \mathrm{L}, 6.9 \%$ at a $25(\mathrm{OH}) \mathrm{D}$ mean concentration of $61.5 \mathrm{nmol} / \mathrm{L}$ and $3.2 \%$ at a $25(\mathrm{OH}) \mathrm{D}$ mean concentration of $160.3 \mathrm{nmol} / \mathrm{L}$, respectively.

2.4. Immundiagnostik. 29 randomly selected EDTA plasma samples with sufficient volume were assayed for $25(\mathrm{OH}) \mathrm{D}$ concentration using a commercially available ELISA kit (Immundiagnostik, Bensheim and Biomedica, Vienna, Austria) according to the manufacturer's instructions. Briefly, in the first incubation step, sample, calibrator, control, the vitamin D binding protein (VDBP) and the VDBP-Antibody are added to the solid phase. $25(\mathrm{OH}) \mathrm{D}$ present in the sample then competes with the tracer, coated on the well for the specific binding site of the binding protein, and the VDBP antibody is bound to the vitamin binding protein. Hence, with increasing concentrations of $25(\mathrm{OH}) \mathrm{D}$ in the sample, the amount of binding protein immobilized to the well via the tracer is reduced. After a washing step to remove unbound components, the quantification of VDBP is achieved by incubation with a host specific peroxidase labelled antibody using TMB as enzyme substrate. An acidic stopping solution is then added to stop the reaction, and the colour converts to yellow. The intensity of the yellow colour is indirectly proportional to the concentration of $25(\mathrm{OH}) \mathrm{D}$ in the sample. The detection limit of the assay was $5.6 \mathrm{nmol} / \mathrm{L}$. According to the information supplied by the manufacturer, the mean intraassay and inter-assay CVs of the $25(\mathrm{OH}) \mathrm{D}$ assay were $10.7 \%$ and $11.8 \%$ to $13.2 \%$, respectively.

2.5. MicroVue. 37 randomly selected EDTA plasma samples with sufficient volume were assayed for $25(\mathrm{OH}) \mathrm{D}$ concentration using a commercially available immunoassay kit (MicroVue, Hannover, Germany) according to the manufacturer's instructions. Briefly, in step 1, standards, controls, and test specimens are added to microplate wells precoated with a primary monoclonal anti-human $25(\mathrm{OH}) \mathrm{D}_{2}$ and $25(\mathrm{OH}) \mathrm{D}_{3}$ antibody. Total $25(\mathrm{OH}) \mathrm{D}\left(\mathrm{D}_{2}\right.$ and $\left.\mathrm{D}_{3}\right)$ in the standards, controls, and samples is dissociated from serum binding proteins and binds to the monoclonal antibody. In step 2, following the first wash cycle, a fixed amount of biotinylated $25(\mathrm{OH}) \mathrm{D}$, in the presence of streptavidin-horseradish peroxidase (HRP), competes with the unlabelled $25(\mathrm{OH}) \mathrm{D}_{2}$ and $25(\mathrm{OH}) \mathrm{D}_{3}$ bound to the monoclonal antibody. At the end of the assay incubation period, a wash cycle stops the competition reaction. In step 3, a chromogenic enzyme substrate is added to each microplate well. The bound HRP conjugate reacts with the substrate, forming a blue colour. After incubation, the enzyme reaction is terminated using a stop chemical, and the colour changes to yellow. The colour intensity of the reaction mixture is proportional to the concentration of total $25(\mathrm{OH}) \mathrm{D}$ present in the test specimens, standards, and controls. According to the information supplied by the manufacturer, the intraassay CVs were $5.7 \%$ at a $25(\mathrm{OH}) \mathrm{D}$ mean concentration of $68.5 \mathrm{nmol} / \mathrm{L}$ and $2.7 \%$ at a $25(\mathrm{OH}) \mathrm{D}$ mean concentration of $107.5 \mathrm{nmol} / \mathrm{L}$, respectively.

2.6. Statistical Analysis. The Wilcoxon matched-pairs signedranks test was used to test for the differences between each method and LC-MS/MS. The correlation between each method and LC-MS/MS was compared using Pearson's correlation coefficient. Agreement in classification of results (vitamin D sufficiency: $\geq 50 \mathrm{nmol} / \mathrm{L}$; vitamin D insufficiency: $<50 \mathrm{nmol} / \mathrm{L}$ ) between each method and LC-MS/MS was assessed using Cohen's kappa (agreement: $<0$, no; 0-0.4, poor; 0.4-0.75, fair to good; and $>0.75$, excellent) [14]. The simple linear regression and Bland-Altman plots were used for the comparison of each method and LC-MS/MS. Data are presented as mean $( \pm S D)$, and the accepted level of significance was $P<0.05$.

\section{Results}

3.1. LC-MS/MS and Eagle Biosciences. The 25(OH)D concentration measured by the Eagle Biosciences assay was significantly lower than the LC-MS/MS assay (Eagle Biosciences: $46.1 \pm 29.0 \mathrm{nmol} / \mathrm{L}, \mathrm{LC}-\mathrm{MS} / \mathrm{MS}: 97.0 \pm 77.0 \mathrm{nmol} / \mathrm{L} ; P=$ 0.001 ) and biased $-50.9 \pm 79.1 \mathrm{nmol} / \mathrm{L}$ (bias $\pm \mathrm{SD} ; 95 \%$ limits of agreement: $-209.1,107.3)$ from the LC-MS/MS assay (Table 1 and Figure 1(b)). There was no significant correlation $(r=0.115, P=0.551)$ between the LC-MS/MS assay and the Eagle Biosciences assay (Table 1). Moreover, there was a considerable misclassification of participants using the cutoff point for vitamin D insufficiency and sufficiency between these two assays. The data of our study showed that 52\% $(15 / 29)$ of participants were misclassified when the results from the Eagle Biosciences assay were compared with those from the LC-MS/MS assay. In addition, there were 14\% (4/29) of participants classified as vitamin D insufficient according to the results from both assays. Cohen's kappa coefficient was -0.048 indicating no agreement (Table 2(a)).

3.2. LC-MS/MS and Immundiagnostik. There was no significant difference in the $25(\mathrm{OH}) \mathrm{D}$ concentration between the Immundiagnostik assay and the LC-MS/MS assay (Immundiagnostik: $82.8 \pm 45.7 \mathrm{nmol} / \mathrm{L}, \mathrm{LC}-\mathrm{MS} / \mathrm{MS}: 97.0 \pm$ $77.0 \mathrm{nmol} / \mathrm{L} ; P=0.770$ ) (Table 1). The Immundiagnostik assay biased $-14.2 \pm 91.0 \mathrm{nmol} / \mathrm{L}$ (bias $\pm \mathrm{SD} ; 95 \%$ limits of agreement: $-196.3,167.9)$ from the LC-MS/MS assay (Figure 1(d)). However, there was no significantly correlation between the LC-MS/MS assay and the Immundiagnostik assay $(r=-0.039, P=0.843)$ (Table 1$)$. The data of this study showed that $48 \%(14 / 29)$ of participants were misclassified when the results from the Immundiagnostik assay were compared with those from the LC-MS/MS assay. In addition, there were only $3 \%(1 / 29)$ of participants classified as vitamin $\mathrm{D}$ insufficient according to the results from both assays. Cohen's kappa coefficient was -0.201 indicating no agreement (Table 2(b)). 


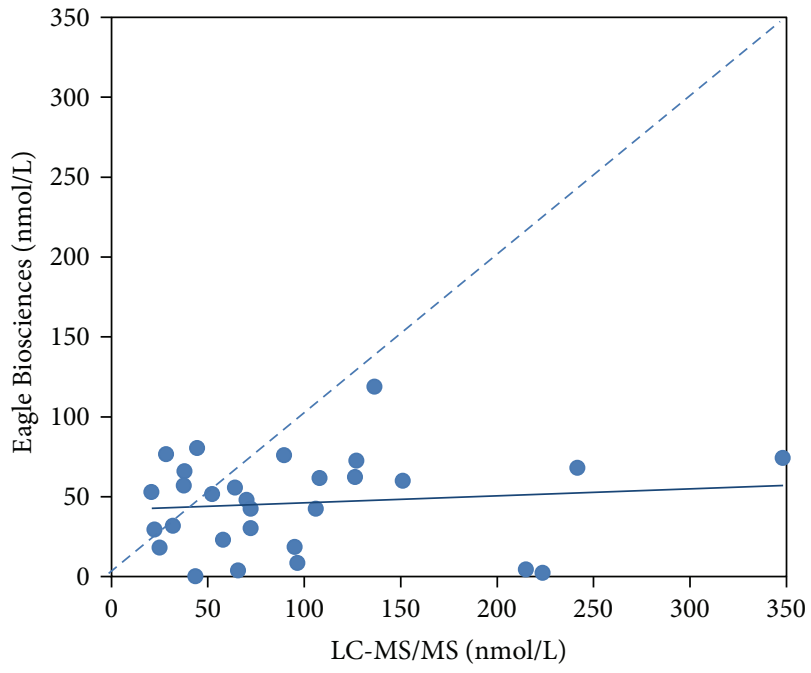

(a)

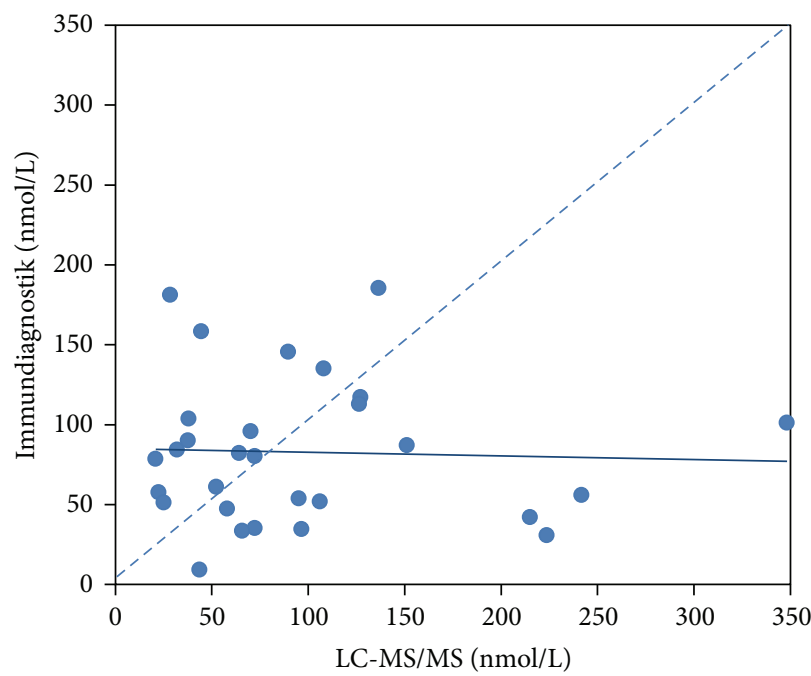

(c)

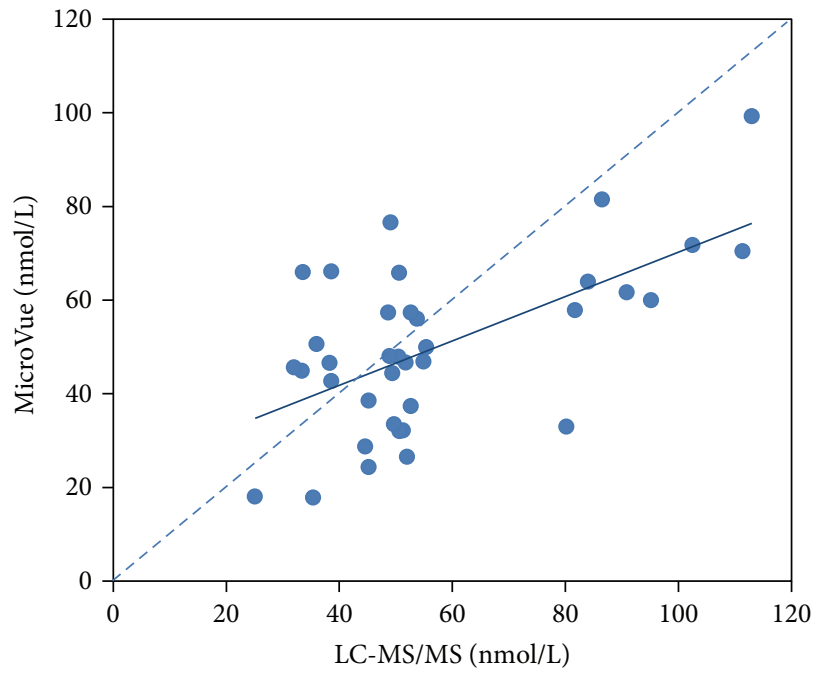

(e)

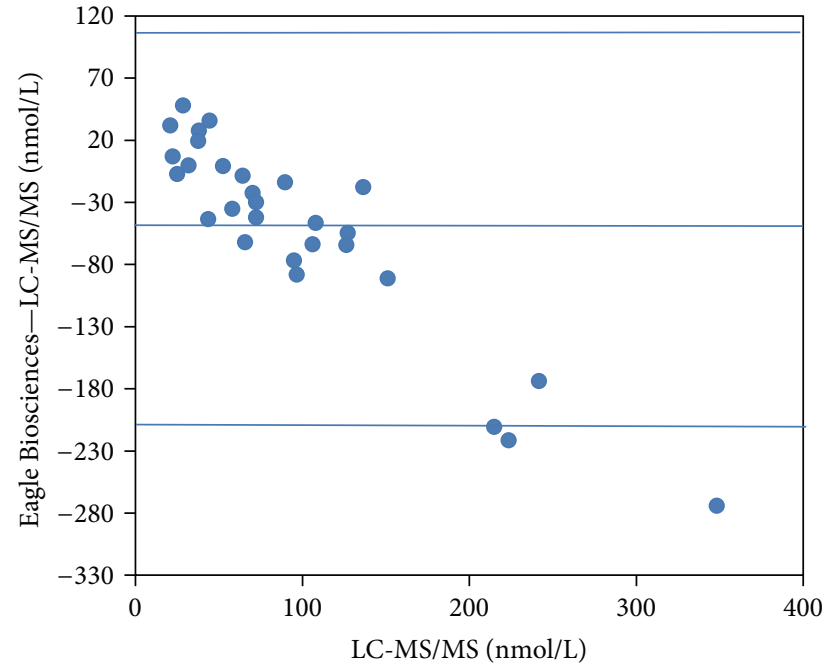

(b)

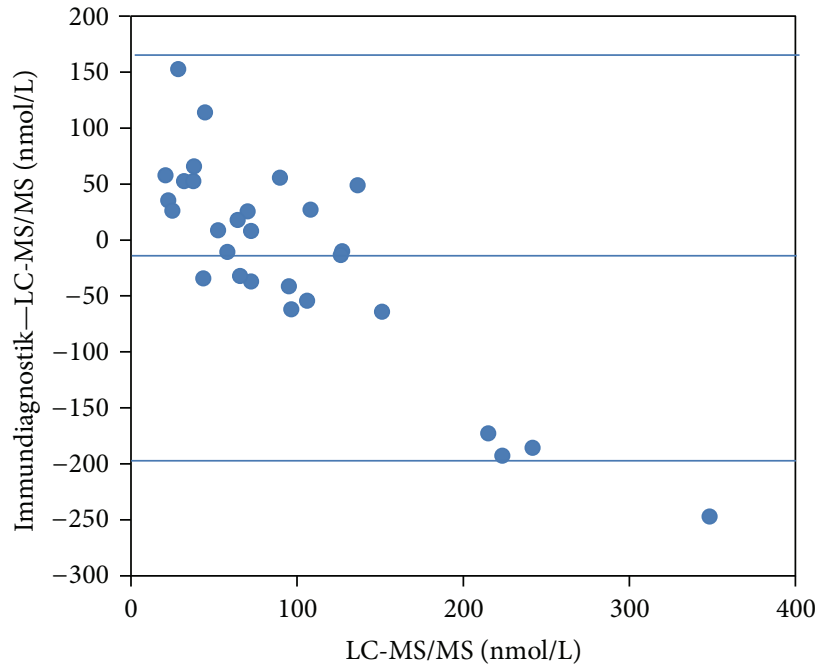

(d)

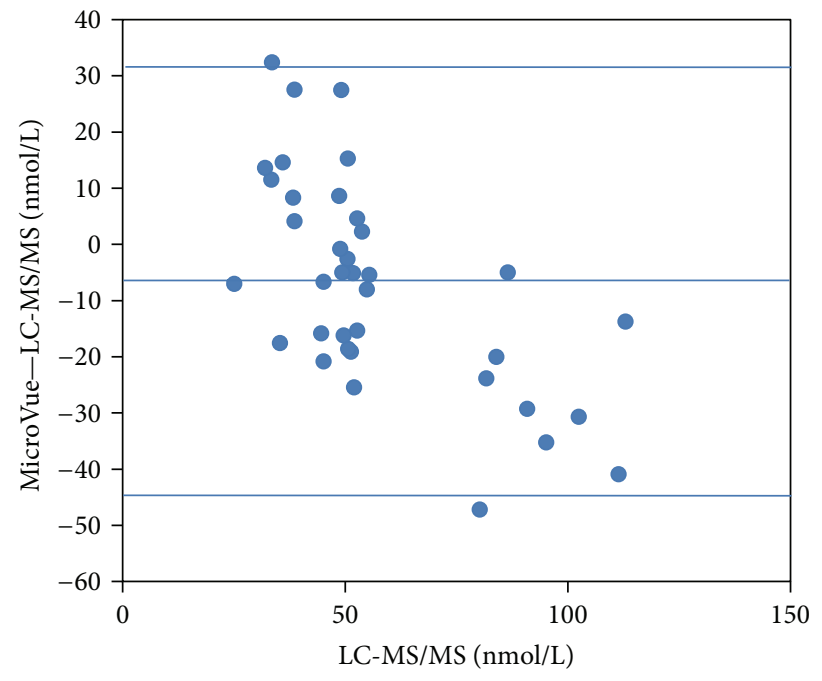

(f)

FIGURE 1: Comparison of the LC-MS/MS method with ELISAs from Eagle Biosciences ((a), (b)), Immundiagnostik ((c), (d)), and MicroVue ((e), (f)) by the simple linear regression ((a), (c), and (e)) and Bland-Altman plots ((b), (d), and (f)). 
TABLE 1: Comparison of mean (SD) 25(OH)D concentrations (nmol/L) from different $25(\mathrm{OH}) \mathrm{D}$ assays.

\begin{tabular}{lccccc}
\hline $\begin{array}{l}\text { Sample size for } \\
\text { comparison bloods }\end{array}$ & LC-MS/MS & Eagle Biosciences & Immundiagnostik & MicroVue & $\begin{array}{c}\text { Wilcoxon } \\
\text { signed-rank test }\end{array}$ \\
\hline$n=29$ & $97.0 \pm 77.0$ & $46.1 \pm 29.0$ & & $P=.001$ & $\begin{array}{c}\text { Pearson's } \\
\text { correlation }\end{array}$ \\
$n=29$ & $97.0 \pm 77.0$ & & $82.8 \pm 45.7$ & $P=.551$ \\
$n=37$ & $57.1 \pm 23.1$ & & $50.0 \pm 18.1$ & $P=.023$ & $P=.843$ \\
\hline
\end{tabular}

TABLE 2: Comparison of the number and percentage of participants classified as vitamin D sufficient and insufficient from different $25(\mathrm{OH}) \mathrm{D}$ assays.

(a)

\begin{tabular}{lcc}
\hline$n=29$ & \multicolumn{2}{c}{ Eagle Biosciences } \\
& $<50 \mathrm{nmol} / \mathrm{L}$ & $\geq 50 \mathrm{nmol} / \mathrm{L}$ \\
\hline LC-MS/MS & & \\
$<50 \mathrm{nmol} / \mathrm{L}$ & $4(14 \%)$ & $5(18 \%)$ \\
$\geq 50 \mathrm{nmol} / \mathrm{L}$ & $10(34 \%)$ & $10(34 \%)$ \\
Cohen's kappa & & -0.048 \\
\hline
\end{tabular}

(b)

\begin{tabular}{|c|c|c|}
\hline \multirow{2}{*}{$n=29$} & \multicolumn{2}{|c|}{ Immundiagnostik } \\
\hline & $<50 \mathrm{nmol} / \mathrm{L}$ & $\geq 50 \mathrm{nmol} / \mathrm{L}$ \\
\hline \multicolumn{3}{|l|}{ LC-MS/MS } \\
\hline$<50 \mathrm{nmol} / \mathrm{L}$ & $1(3 \%)$ & $8(28 \%)$ \\
\hline$\geq 50 \mathrm{nmol} / \mathrm{L}$ & $6(21 \%)$ & $14(48 \%)$ \\
\hline Cohen's kappa & \multicolumn{2}{|c|}{-0.201} \\
\hline
\end{tabular}

(c)

\begin{tabular}{|c|c|c|}
\hline \multirow{2}{*}{$n=37$} & \multicolumn{2}{|c|}{ MicroVue } \\
\hline & $<50 \mathrm{nmol} / \mathrm{L}$ & $\geq 50 \mathrm{nmol} / \mathrm{L}$ \\
\hline \multicolumn{3}{|l|}{ LC-MS/MS } \\
\hline$<50 \mathrm{nmol} / \mathrm{L}$ & $12(32 \%)$ & $5(14 \%)$ \\
\hline$\geq 50 \mathrm{nmol} / \mathrm{L}$ & $9(24 \%)$ & $11(30 \%)$ \\
\hline Cohen's kappa & \multicolumn{2}{|c|}{0.251} \\
\hline
\end{tabular}

3.3. LC-MS/MS and MicroVue. The 25(OH)D concentration measured by the MicroVue assay was significantly lower than the LC-MS/MS assay (MicroVue: $50.0 \pm 18.1 \mathrm{nmol} / \mathrm{L}$; LCMS/MS: $57.1 \pm 23.1 \mathrm{nmol} / \mathrm{L}, P=0.023)$ and biased $-7.2 \pm$ $18.9 \mathrm{nmol} / \mathrm{L}$ (bias $\pm \mathrm{SD}$; $95 \%$ limits of agreement: -44.9 , 30.6) from the LC-MS/MS assay (Table 1 and Figure 1(f)). Nevertheless, there was a significant positive correlation between the LC-MS/MS assay and the MicroVue assay $(r=$ $0.603, P=0.001$ ) (Table 1). The data of this study showed that $38 \%(9 / 37)$ of participants were misclassified when the results from the MicroVue assay were compared with those from the LC-MS/MS assay. Moreover, there were 32\% (12/37) of participants classified as vitamin D insufficient according the results from both assays. Cohen's kappa coefficient was 0.251 indicating poor agreement (Table 2(c)).

\section{Discussion}

To our knowledge, this is the first report to compare the accuracy and clinical implications of the Eagle Biosciences,
Immundiagnostik, and MicroVue commercial immunoassay kits with the LC-MS/MS method for the measurement of plasma $25(\mathrm{OH}) \mathrm{D}$ concentration. The main findings were that there were negative biases in the Eagle Biosciences, Immundiagnostik, and MicroVue assays compared with the LC-MS/MS assay. Furthermore, there was no significant correlation between Eagle Biosciences and LC-MS/MS as well as Immundiagnostik and LC-MS/MS. Nevertheless, there was a positive correlation between the MicroVue and LCMS/MS assay. In addition, there was a considerable misclassification of participants using the cut-off point for vitamin $\mathrm{D}$ insufficiency and sufficiency between each assay and the LC-MS/MS assay. The results of the present study showed no agreement in classification of participants defined as vitamin D sufficient and insufficient between Eagle Biosciences and LC-MS/MS as well as Immundiagnostik and LC-MS/MS and only poor agreement between MicroVue and LC-MS/MS.

The reasons for the negative biases in the Eagle Biosciences, Immundiagnostik, and MicroVue assays compared with the LC-MS/MS assay are not clear. However, a confounding factor for the variable results might be due to the strong binding of $25(\mathrm{OH}) \mathrm{D}$ to VDBP. The serum $25(\mathrm{OH}) \mathrm{D}$ concentration cannot be measured accurately unless it is released from VDBP and the strong protein binding of $25(\mathrm{OH}) \mathrm{D}$ requires the employment of suitable conditions to release $25(\mathrm{OH}) \mathrm{D}$ from VDBP $[1,2]$. In the LC-MS/MS assay of the present study, $25(\mathrm{OH}) \mathrm{D}_{2}$ and $25(\mathrm{OH}) \mathrm{D}_{3}$ were extracted from plasma samples using isolute $\mathrm{C} 18$ solid phase extraction cartridges. Nevertheless, all the immunoassays that were examined in this study employed monoclonal $25(\mathrm{OH}) \mathrm{D}$ antibodies to bind $25(\mathrm{OH}) \mathrm{D}$ from VDBP. The competition between the specific antibody and VDBP in plasma samples could make these immunoassays difficult to control and may lead to poor agreement with the LCMS/MS assay $[10,15]$. Another confounding factor might be due to the quantitation of plasma $25(\mathrm{OH}) \mathrm{D}_{2}$ and $25(\mathrm{OH}) \mathrm{D}_{3}$. Because isotope dilution LC-MS/MS methods can simultaneously and accurately quantitate both $25(\mathrm{OH}) \mathrm{D}_{2}$ and $25(\mathrm{OH}) \mathrm{D}_{3}$, it can be considered to be the gold standard method for the measurement of plasma or serum 25(OH)D levels $[1,2,9]$. The present immunoassays cannot measure the concentration of $25(\mathrm{OH}) \mathrm{D}_{2}$ and $25(\mathrm{OH}) \mathrm{D}_{3}$ independently. It has been reported that there was an underestimation of plasma $25(\mathrm{OH}) \mathrm{D}_{2}$ concentration in several commercial immunoassays which resulted in marked variations of the total plasma $25(\mathrm{OH}) \mathrm{D}$ levels $[1,2]$. Nevertheless, the results of the present study showed that there was a positively correlation between the MicroVue ELISA and LC-MS/MS methods and had better agreement than the other two commercial ELISAs that were examined. It might be due to 
the employment of both monoclonal anti-human $25(\mathrm{OH}) \mathrm{D}_{2}$ and $25(\mathrm{OH}) \mathrm{D}_{3}$ antibody in the MicroVue assay.

There was a considerable misclassification of participants using the cut-off point for vitamin D insufficiency and sufficiency in the Eagle Biosciences, Immundiagnostik, and MicroVue assays compared with the LC-MS/MS assay. In healthy humans, plasma $25(\mathrm{OH}) \mathrm{D}$ serum levels $>100 \mathrm{nmol} / \mathrm{L}$ are defined as optimal vitamin D status, and levels from 50 to $100 \mathrm{nmol} / \mathrm{L}$ are defined as adequate. Serum levels of 25(OH)D $<50 \mathrm{nmol} / \mathrm{L}$ are proposed to define inadequate vitamin $\mathrm{D}$ status, and values $<30 \mathrm{nmol} / \mathrm{L}$ represent vitamin D deficiency [8]. Therefore, the commonly used cut-off point for vitamin $\mathrm{D}$ insufficiency in clinical practice and research reports is the threshold concentration of $25(\mathrm{OH}) \mathrm{D}$ of $<50 \mathrm{nmol} / \mathrm{L}$ [11]. On the basis of the present data, we found that $52 \%$, $48 \%$, and $38 \%$ of participants were misclassified when the results from the Eagle Biosciences, Immundiagnostik and MicroVue assays were compared with those from the LCMS/MS assay, respectively. In addition, according to Cohen's kappa coefficient from this study (kappa: -0.201 0.251), the results showed the poor agreement in classification of participants defined as vitamin D sufficient and insufficient between each method and LC-MS/MS [14]. Measurement of plasma $25(\mathrm{OH}) \mathrm{D}$ concentration is widely used in clinical practice and research reports to assess vitamin $\mathrm{D}$ status of participants. Our results indicated that the assessment of vitamin $\mathrm{D}$ status seems to be influenced substantively by the $25(\mathrm{OH}) \mathrm{D}$ assay being used. Given the large proportion of misclassified participants using the present immunoassays, it is important to discover if there are any more reliable commercial immunoassays of serum $25(\mathrm{OH}) \mathrm{D}$, which are suitable for clinicians and researchers.

In conclusion, the present study demonstrated that there were negative biases and the considerable misclassification of participants using the cut-off point for vitamin D insufficiency and sufficiency using the Eagle Biosciences, Immundiagnostik, and MicroVue assays compared with the LC-MS/MS assay. Without using the most reliable $25(\mathrm{OH}) \mathrm{D}$ assays, the assessment of vitamin $\mathrm{D}$ status of participants remains very doubtful.

\section{Acknowledgment}

The authors gratefully acknowledge the funding support from the Gatorade Sport Science Institute.

\section{References}

[1] W. D. Fraser and A. M. Milan, "Vitamin D assays: past and present debates, difficulties, and developments," Calcified Tissue International, vol. 92, no. 2, pp. 118-127, 2013.

[2] A. M. Wallace, S. Gibson, A. de la Hunty, C. LambergAllardt, and M. Ashwell, "Measurement of 25-hydroxyvitamin $\mathrm{D}$ in the clinical laboratory: current procedures, performance characteristics and limitations," Steroids, vol. 75, no. 7, pp. 477488,2010 .

[3] M. F. Holick, "Deficiency of sunlight and vitamin D," BMJ, British Medical Journal, vol. 336, no. 7657, pp. 1318-1319, 2008.
[4] D. E. Larson-Meyer and K. S. Willis, "Vitamin D and athletes," Current Sports Medicine Reports, vol. 9, no. 4, pp. 220-226, 2010.

[5] D. J. Berry, K. Hesketh, C. Power, and E. Hyppönen, "Vitamin D status has a linear association with seasonal infections and lung function in British adults," British Journal of Nutrition, vol. 106, no. 9, pp. 1433-1440, 2011.

[6] A. A. Ginde, J. M. Mansbach, and C. A. Camargo Jr., "Association between serum 25-hydroxyvitamin D level and upper respiratory tract infection in the Third National Health and Nutrition Examination Survey," Archives of Internal Medicine, vol. 169, no. 4, pp. 384-390, 2009.

[7] F. Baeke, T. Takiishi, H. Korf, C. Gysemans, and C. Mathieu, "Vitamin D: modulator of the immune system," Current Opinion in Pharmacology, vol. 10, no. 4, pp. 482-496, 2010.

[8] G. L. Close, J. Russell, J. N. Cobley et al., "Assessment of vitamin D concentration in non-supplemented professional athletes and healthy adults during the winter months in the UK: implications for skeletal muscle function," Journal of Sports Sciences, vol. 31, no. 4, pp. 344-353, 2013.

[9] J. E. Zerwekh, "Blood biomarkers of vitamin D status," American Journal of Clinical Nutrition, vol. 87, no. 4, pp. 1087S-1091S, 2008.

[10] M. Herrmann, T. Harwood, O. Gaston-Parry et al., "A new quantitative LC tandem mass spectrometry assay for serum 25hydroxy vitamin D," Steroids, vol. 75, no. 13-14, pp. 1106-1112, 2010.

[11] J. K. C. Lai, R. M. Lucas, E. Banks, and A.-L. Ponsonby, "Variability in vitamin D assays impairs clinical assessment of vitamin D status," Internal Medicine Journal, vol. 42, no. 1, pp. 43-50, 2012.

[12] H. J. Roth, H. Schmidt-Gayk, H. Weber, and C. Niederau, "Accuracy and clinical implications of seven 25-hydroxyvitamin D methods compared with liquid chromatography-tandem mass spectrometry as a reference," Annals of Clinical Biochemistry, vol. 45, part 2, pp. 153-159, 2008.

[13] A.-M. Tolppanen, A. Sayers, W. D. Fraser, and D. A. Lawlor, "Association of serum 25-hydroxyvitamin D3 and D2 with academic performance in childhood: findings from a prospective birth cohort," Journal of Epidemiology and Community Health, vol. 66, no. 12, pp. 1137-1142, 2012.

[14] J. L. Fleiss, B. A. Levin, and M. C. Paik, Statistical Methods for Rates and Proportions, J. L. Fleiss, B. Levin, M. C. Paik, Eds., Wiley-Interscience, Hoboken, NJ, USA, 3rd edition, 2003.

[15] C.-J. L. Farrell, S. Martin, B. McWhinney, I. Straub, P. Williams, and M. Herrmann, "State-of-the-art vitamin D assays: a comparison of automated immunoassays with liquid chromatography-tandem mass spectrometry methods," Clinical Chemistry, vol. 58, no. 3, pp. 531-542, 2012. 


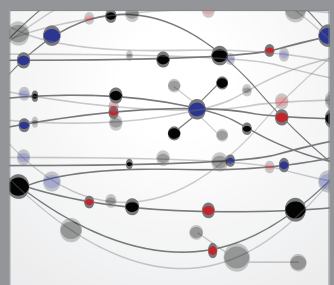

The Scientific World Journal
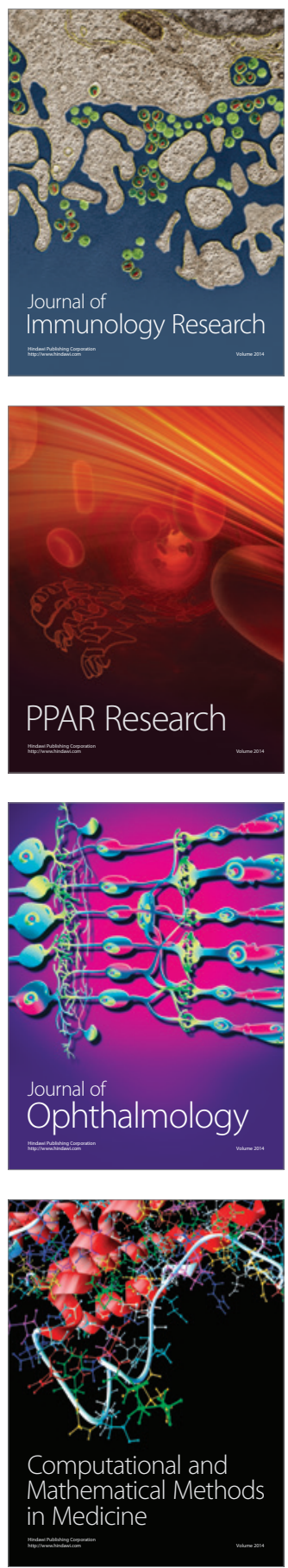

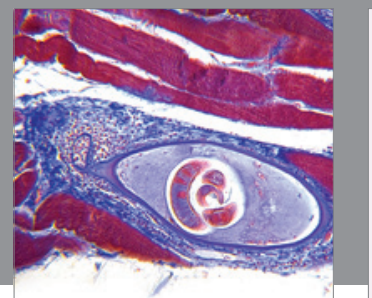

Gastroenterology

Research and Practice
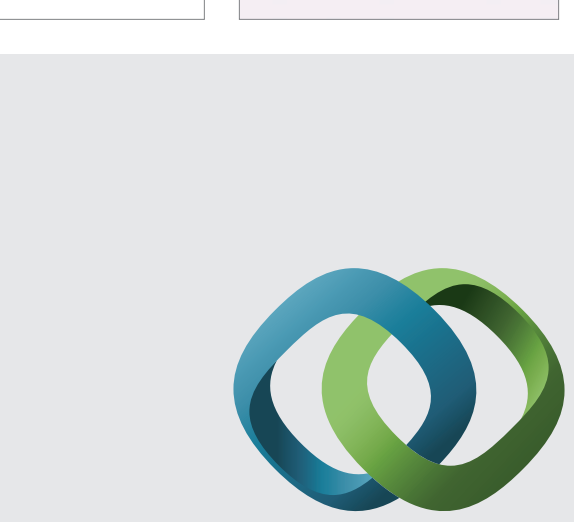

\section{Hindawi}

Submit your manuscripts at

http://www.hindawi.com
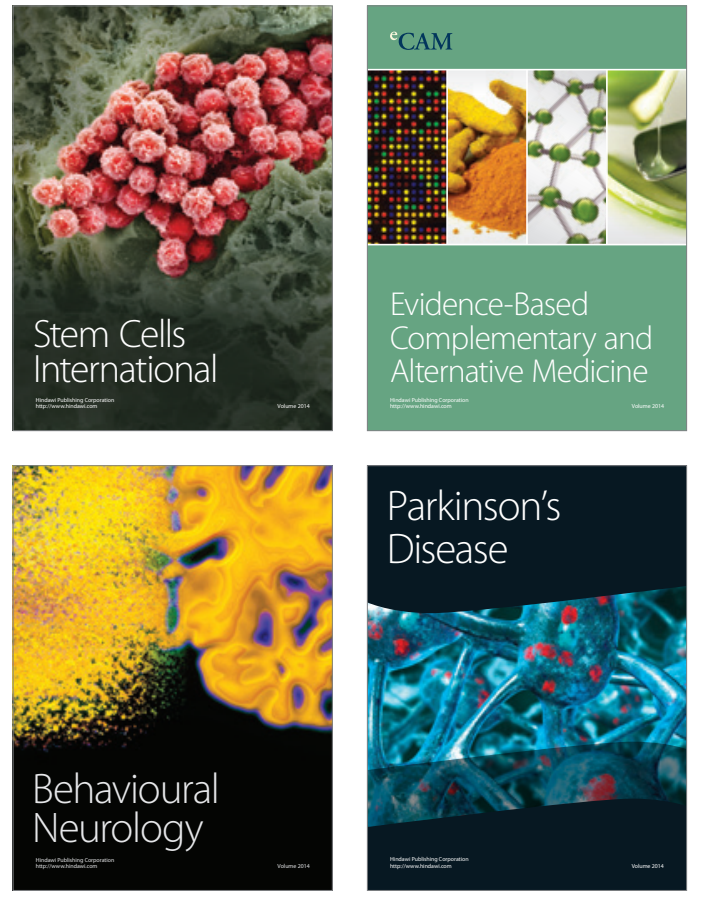
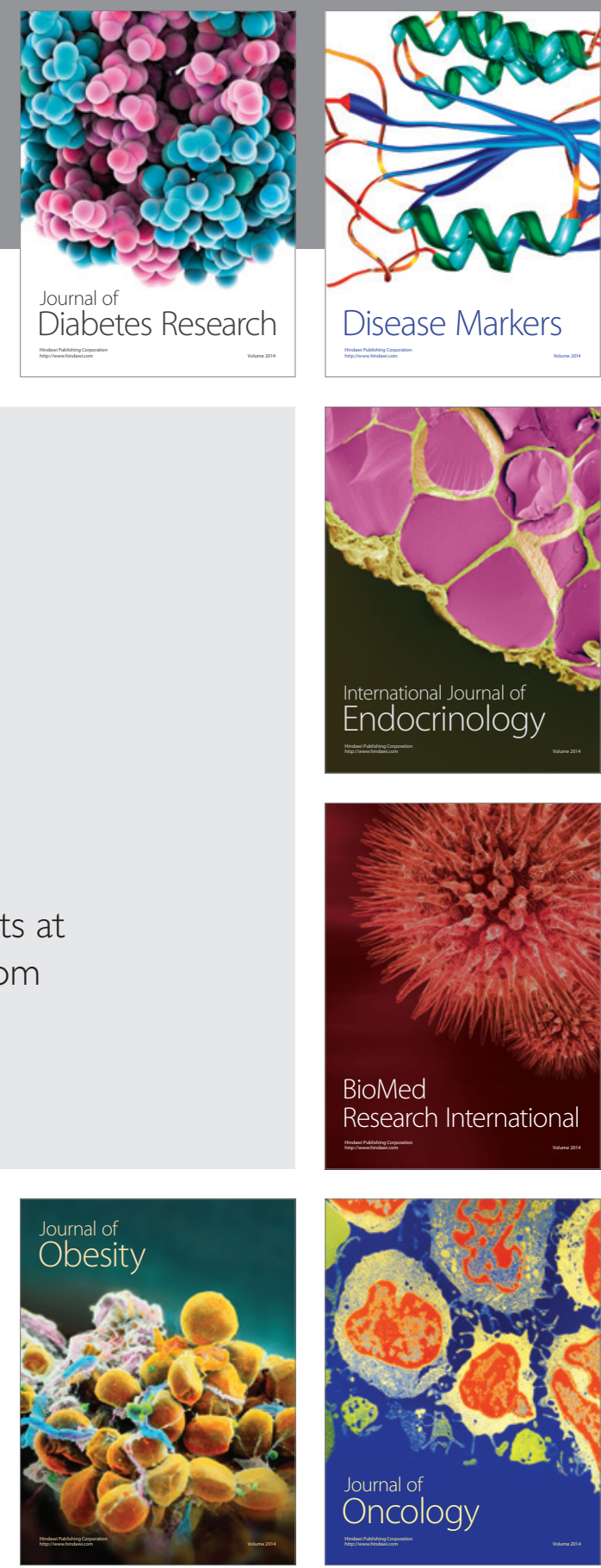

Disease Markers
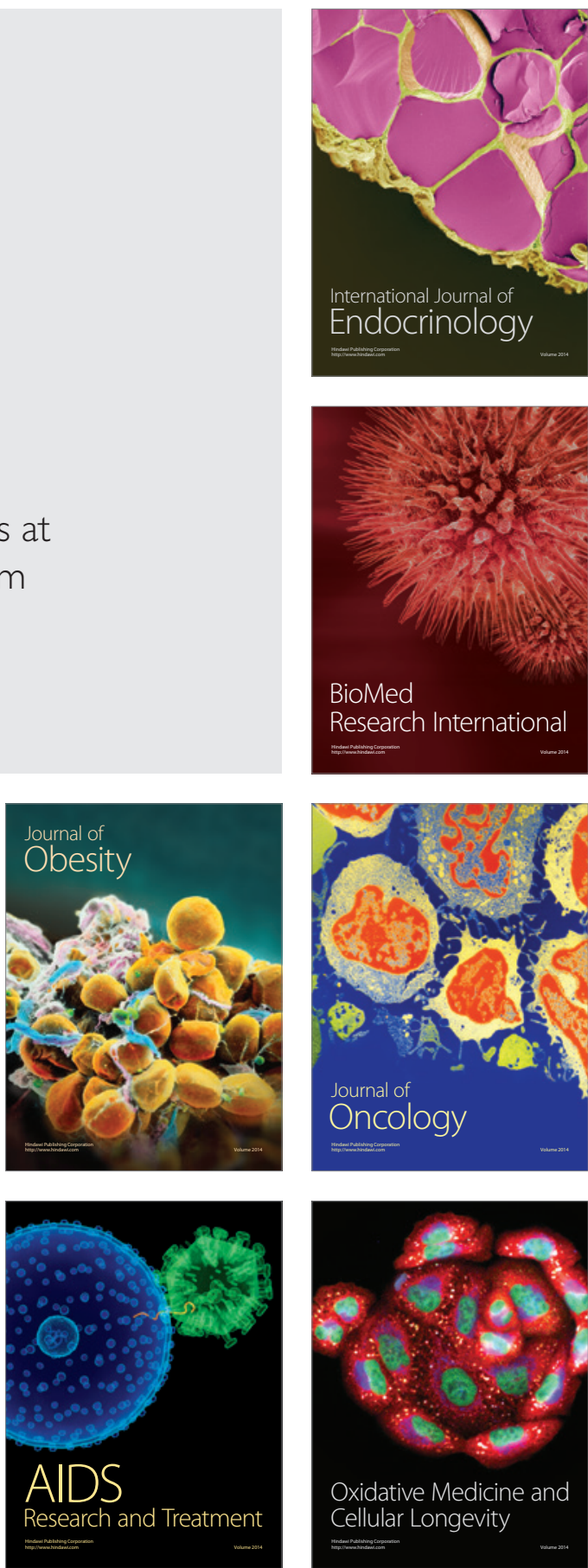